\title{
BIOCHEMICAL ASSESSMENT OF MYOCARDIAL INJURY AFTER CARDIAC SURGERY: EFFECTS OF A PLATELET ACTIVATING FACTOR ANTAGONIST, BILATERAL INTERNAL THORACIC ARTERY GRAFTS, AND CORONARY ENDARTERECTOMY
}

David P. Taggart, MD, FRCS
Objective: Platelet activating factor antagonists reduce ischemia-reperfusion injury in experiments, but there is no supportive clinical evidence.

Methods: A single-center, double-blind, minimized, placebo-controlled, randomized trial of low-dose $(10 \mathrm{mg})$ or high-dose $(100 \mathrm{mg})$ platelet activating factor antagonist was conducted in 150 patients undergoing coronary artery bypass grafting. Myocardial injury was determined by serial measurements of the MB isoenzyme of creatine kinase and cardiac troponin T. The effects of single or bilateral internal thoracic artery grafting and coronary endarterectomy on myocardial injury were also assessed.

Results: The placebo and platelet activating factor antagonist groups were similar with respect to preoperative, intraoperative, and postoperative factors. Four patients $(2.7 \%)$ died before discharge, 3 from cardiac events. Thirteen patients $(9 \%)$ had biochemical evidence of myocardial infarction, of whom 3 died. Stepwise multiple regression analysis demonstrated that duration of cardiopulmonary bypass was the most important determinant of elevations in creatine kinase MB isoenzyme and cardiac troponin T up to 6 hours after the operation and that the use of a platelet activating factor antagonist and the number of internal thoracic artery grafts did not influence myocardial injury at any time. Endarterectomy was performed in 11 patients (7\%), of whom 6 (55\%) had biochemically defined myocardial infarction and of whom 1 died (9\%). Endarterectomy was the most important determinant of elevated levels of creatine kinase MB isoenzyme and cardiac troponin $\mathrm{T} 24$ and 48 hours after the operation.

Conclusion: Platelet activating factor antagonists do not reduce perioperative myocardial injury. Bilateral and single internal thoracic artery grafting results in similar levels of myocardial injury, whereas endarterectomy is frequently associated with biochemical evidence of myocardial injury. ( $J$ Thorac Cardiovasc Surg 2000;120:651-9)
S pecific biochemical markers demonstrate that some $\mathcal{S}_{\text {degree of myocardial injury is an inevitable conse- }}$

From Oxford Heart Centre, John Radcliffe Hospital, Oxford, United Kingdom.

Funded by British Biotech Pharmaceuticals Ltd, Watlington Rd, Oxford, OX4 5LY, United Kingdom.

Received for publication Sept 24, 1999; revisions requested Dec 1, 1999; revisions received Jan 21, 2000; accepted for publication Feb 9, 2000.

Address for reprints: D. P. Taggart, MD, FRCS, Consultant Cardiothoracic Surgeon, Oxford Heart Centre, John Radcliffe Hospital, Oxford OX3 9DU, United Kingdom

(E-mail: david.taggart@orh.anglox.nhs.uk).

Copyright (C) 2000 by The American Association for Thoracic Surgery

0022-5223/2000 $\$ 12.00+0 \quad \mathbf{1 2 / 1 / 1 0 6 3 2 5}$

doi:10.1067/mtc.2000.106325 quence of cardiac operations. ${ }^{1-4}$ The prevalence of perioperative myocardial infarction is reported between $5 \%$ and $21 \% .^{5-10}$ The pathophysiology of postoperative myocardial injury is complex and results from a combination of ischemia-reperfusion injury ${ }^{11,12}$ and the systemic inflammatory response syndrome. ${ }^{13,14}$

Platelet activating factor (PAF), whose circulating concentration increases by around $350 \%$ during cardiopulmonary bypass (CPB), ${ }^{15}$ regulates both responses, which depend on activation and adhesion of circulating leukocytes to microvascular endothelium. ${ }^{16}$ PAF, a glycerol phospholipid synthesized by a variety of cells, is a particularly potent bioactive mediator of inflammation and produces cell damage by several mechanisms. ${ }^{17}$ As a major stimulator of neutrophil integrin expression, PAF controls neutrophil activa- 
tion, chemotaxis, and diapedesis and is responsible for neutrophil-mediated tissue injury. ${ }^{17}$ At a local level, PAF is a major endogenous mediator of neutrophil aggregation in ischemia-reperfusion injury, ${ }^{18}$ and several experimental models have reported the efficacy of PAF antagonists in abolishing or reducing its consequences. ${ }^{17-20}$ In addition to causing direct myocardial injury, PAF has several adverse hemodynamic consequences, including coronary vasospasm, negative inotropy, and an increase in cardiac arrhythmia. ${ }^{17-20}$ To date, however, there has been no report of the ability of a PAF antagonist to reduce myocardial injury in clinical practice.

The primary aim of this study was to examine the potential of a PAF antagonist to reduce myocardial injury in coronary artery bypass grafting. In a singlecenter, double-blind, minimized, placebo-controlled, randomized trial, the effects of low-dose $(10 \mathrm{mg})$ or high-dose $(100 \mathrm{mg})$ PAF antagonist were assessed by serial measurements of the MB isoenzyme of creatine kinase (CK-MB) and cardiac troponin $\mathrm{T}(\mathrm{cTnT})$. My colleagues and $\mathrm{I}^{1-4}$ have previously used these markers to quantify myocardial injury and to assess interventions in adults and children undergoing cardiac operations. A secondary aim was to examine the effects of single or bilateral internal thoracic artery (ITA) grafting and coronary endarterectomy on myocardial injury.

\section{Methods}

Patients. The 150 patients undergoing CPB in the current study were enrolled in a randomized controlled trial of a PAF antagonist (lexipafant) between February 1996 and March 1997. The Central Oxford Research Ethics Committee approved the study, and written informed consent was obtained from all patients.

The inclusion criteria for the study included patients undergoing first-time coronary artery bypass grafting for angiographically demonstrated coronary stenoses. Exclusion criteria included emergency surgery, significantly impaired ventricular function (ejection fraction $<30 \%$ ), or a previous cerebrovascular accident.

Lexipafant (BB-882) is a PAF antagonist developed by British Biotech Pharmaceuticals Ltd, Oxford, United Kingdom. It is well tolerated with potent ex vivo PAF antagonism demonstrated at both blood (platelet aggregation) and tissue level (intradermal weal and flare response). Lexipafant was administered intravenously in a total dose of $10 \mathrm{mg}(0.4-$ $\mathrm{mg}$ bolus followed by $0.4 \mathrm{mg} / \mathrm{h}$ for 24 hours) or $100 \mathrm{mg}$ (4$\mathrm{mg}$ bolus followed by $4 \mathrm{mg} / \mathrm{h}$ for 24 hours). A standard dose of $100 \mathrm{mg}$ in 24 hours provides steady state levels of drug between 50 and $150 \mathrm{ng} / \mathrm{mL}$. Pharmacokinetic extrapolations predict that a level of $2 \mathrm{ng} / \mathrm{mL}$ is sufficient to block exogenous effects of PAF such as platelet aggregation. The levels needed for a therapeutic effect are uncertain but are expected to be high to block endogenous PAF released in high concentration in direct cell-to-cell interaction. In volunteers, steady state blood levels in the range of 500 to $800 \mathrm{ng} / \mathrm{mL}$ have been achieved without untoward effect.

Power calculations. A sample size of 50 patients per group was sufficient to show, with at least $80 \%$ power, a significant difference in mean changes from baseline in CK-MB levels at 24 hours, assuming a population mean change from baseline in an active group equal to $15 \%$ of the placebo mean change (ie, an $85 \%$ reduction) and population standard deviations (SDs) of changes in each group of $48 \mathrm{ng} / \mathrm{mL}$. The estimates of the placebo mean change and of the within-group $\mathrm{SD}$ were based on blinded data from the combined placebo and active groups in study D06/IVB/252.

Randomization. Treatment allocation was by a doubleblind process of minimization using the British Biotech minimization program. Minimization was used so that the 2 treatment groups would be balanced with respect to age $(<40$, $40-49,59-59,60-69,>70$ years), sex, number of vessels affected (left main stem, three vessels, one or two vessels), previous percutaneous transluminal coronary angioplasty (yes/no), surgeon (David P. Taggart or Ravi Pillai), aspirin therapy (yes/no), and left ventricular function (normal/ impaired). When a patient was to be entered into the study, the relevant details were faxed to British Biotech, and the computer program determined the treatment group to which the patient was to be allocated; the patient was assigned to the next available subject number from the pre-determined randomization schedule. Details of the allocation were stored in the computer.

Anesthesia. All patients received the same anesthetic regimen. Premedication was achieved with morphine (10-15 mg) and scopolamine $(0.3-0.4 \mathrm{mg})$. Anesthesia was induced with fentanyl (1 mg), pancuronium ( $8 \mathrm{mg}$ ), and etomidate (4-10 mg). Anesthesia was maintained with a combination of oxygen, nitrous oxide, and halothane before CPB and with propofol (6 $\mathrm{mg} / \mathrm{kg}$ per hour) during CPB. Benzodiazepines were not used.

Surgery. The operations were performed by two consultant surgeons using intermittent aortic crossclamping and fibrillation (135 patients) or by supervised surgeons in training using antegrade cold crystalloid cardioplegia (1 L St Thomas' Hospital solution) in 15 patients.

CPB. CPB was achieved with a pump flow rate of $2.4 \mathrm{~L}$. $\mathrm{m}^{2} \cdot \min$ at normothermia with the temperature allowed to drift to $34^{\circ} \mathrm{C}$. Topical cooling was not used, and there was no direct or indirect left ventricular venting. A Cobe CML membrane oxygenator (Cobe Cardiovascular, Inc, Arvada, Calif) and a roller pump producing nonpulsatile flow were used without an arterial line filter. Alpha-stat control of acid-base management was used and the mean arterial pressure was maintained between 50 and $60 \mathrm{~mm} \mathrm{Hg}$ with pharmacologic manipulation if necessary.

Postoperative management. All patients were managed by the same standardized cardiovascular, respiratory, and renal protocols aimed at early extubation. Timing of extubation was managed by the nursing staff in alert, hemodynamically stable patients capable of maintaining self-ventilation. 
Volume 120, Number 4

Table I. Preoperative, intraoperative, and postoperative data on patients

\begin{tabular}{|c|c|c|c|c|c|}
\hline \multicolumn{6}{|c|}{ PAF antagonist } \\
\hline & Placebo & $10 \mathrm{mg}$ & $100 \mathrm{mg}$ & Total & $\mathrm{P}$ value \\
\hline No. & 50 & 50 & 50 & 150 & \\
\hline Age (y) & $62(8)$ & $63(9)$ & $62(10)$ & $62(9)$ & .9 \\
\hline Weight (kg) & $82(13)$ & 85 (14) & $83(18)$ & $83(15)$ & .7 \\
\hline Male sex (\%) & $84 \%$ & $92 \%$ & $86 \%$ & $87 \%$ & .5 \\
\hline Urgent operation (\%) & $25 \%$ & $21 \%$ & $29 \%$ & $25 \%$ & 6 \\
\hline Aspirin use (\%) & $26 \%$ & $26 \%$ & $29 \%$ & $27 \%$ & .9 \\
\hline Grafts & $2.8(0.6)$ & $2.8(0.6)$ & $2.7(0.6)$ & $2.8(0.6)$ & .6 \\
\hline CPB time (min) & $64(18)$ & $65(15)$ & $67(22)$ & $65(18)$ & .7 \\
\hline Cardioplegia (\%) & $2 \%$ & $12 \%$ & $16 \%$ & $10 \%$ & .06 \\
\hline Veins, LITA, BITA (\%) & $8,48,44$ & $12,62,26$ & $4,64,32$ & $8,58,34$ & .2 \\
\hline Endarterectomy (\%) & $2 \%$ & $6 \%$ & $14 \%$ & $7 \%$ & .06 \\
\hline Myocardial infarction (\%) & $6 \%$ & $6 \%$ & $14 \%$ & $9 \%$ & .3 \\
\hline Ventilation (h) & $3.5(2.3)$ & $4.3(4.3)$ & $5.3(5.6)$ & $4.4(4.3)$ & .17 \\
\hline Discharge (d) & $6.3(1.9)$ & $6.8(4.0)$ & $6.8(3.7)$ & $6.6(3.3)$ & .7 \\
\hline
\end{tabular}

Figures are presented as mean (SD) or percentage. $P$ value is assessed by analysis of variance or Kruskal-Wallis, as appropriate. LITA, Left internal thoracic artery; BITA, bilateral internal thoracic artery.

Measurement of CK-MB and cTnT. Blood samples were taken for analysis of cTnT and CK-MB pre-dose and at 1, 6, 24, and 48 hours after CPB. All cTnT assays used heparinized plasma samples. CK-MB assays used plasma samples treated with ethylenediaminetetraacetic acid in all except 20 subjects, in whom heparinized plasma samples were used. Assays of cTnT were done at the Analytical Unit, St George's Hospital Medical School, London, with the use of the ES-300 Immunoassay analyzer, which carries out a 1step enzyme-linked immunosorbent assay using a mixture of two anti-cTnT monoclonal antibodies. Boehringer Mannheim Ltd, East Sussex, produced the kit. The lower limit of quantification was $0.02 \mu \mathrm{g} / \mathrm{L}$. CK-MB was determined at The Analytical Unit, St George's Hospital Medical School, with the use of a paramagnetic-particle, chemiluminescent immunoassay on the Access immunoassay system. Sanofi Diagnostics Pasteur Ltd, Surrey, produced reagents. The lower limit of quantification was $0.3 \mu \mathrm{g} / \mathrm{L}$.

Definition of perioperative myocardial infarction. Perioperative myocardial infarction was defined as a rise in both CK-MB and cTnT at 24 and/or 48 hours above the respective values at 6 hours.

Statistical analysis. Statistical analysis was undertaken with the SPSS computer program (version 9.0, SPSS, Inc, Chicago, Ill). Data are presented as mean (SD) or median (interquartile range) as appropriate. Areas under the curve were computed by means of the linear trapezoid rule and log transformed to account for skewed distribution. Demographic data among the 3 groups were combared by analysis of variance or the Kruskal-Wallis test as appropriate.

Minimization was employed during randomization to ensure equal distribution of known factors such as age, sex, number of vessels affected, previous angioplasty, surgeon, aspirin therapy, and left ventricular function. Biochemical markers of myocardial injury (dependent variable) in the 3 groups were analyzed by stepwise linear regression analysis; randomization group, differing use of ITA grafts, duration of $\mathrm{CPB}$, presence or absence of endarterectomy, and method of myocardial protection were used as independent variables.

\section{Results}

Patient characteristics and intraoperative and postoperative data are summarized in Table I. The placebo and low- and high-dose PAF antagonist groups were similar with respect to age, sex, urgency of operation, preoperative aspirin use, number and type of grafts, and CPB times.

There were 4 deaths within 7 days of surgery (2.7\%), 3 from cardiac events and 1 from ischemic bowel. Data from these patients are included in the biochemical analysis. Thirteen patients $(9 \%)$ had biochemical evidence of perioperative myocardial infarction, of whom 3 died. There was no significant difference among the groups with respect to perioperative myocardial infarction or death.

Two patients had an elevated preoperative cTnT $(>0.2 \mu \mathrm{g} / \mathrm{L}), 1$ of whom had a perioperative myocardial infarction and the other an uneventful outcome.

The mean postoperative ventilation time and time to discharge were not significantly different in the 3 groups.

Biochemical pattern of myocardial injury. CK$\mathrm{MB}$ and cTnT concentrations increased from pre-dose to peak values between 6 and 24 hours after CPB, declining by 48 hours except in patients with perioperative myocardial infarction, in whom peak values were observed between 24 and 48 hours (Figs 1 and 2). 


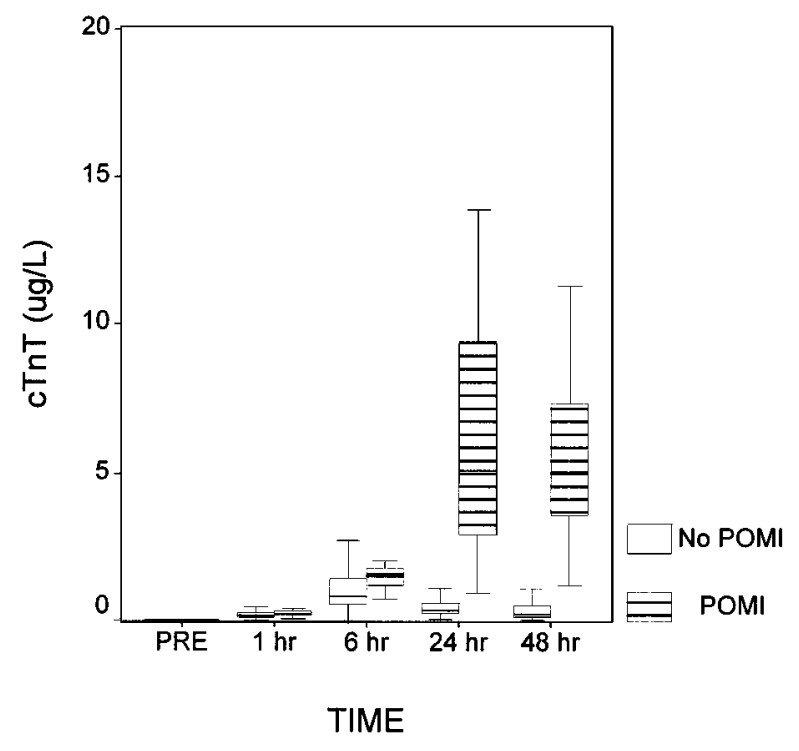

Fig 1. CK-MB in patients with and without perioperative myocardial infarction. The figure is presented as a box-plot and whiskers. The central horizontal line represents the median, and the bottom and top of the box represent the 25th (lower quartile) and 75th (upper quarter) percentiles, respectively. The whiskers represent smaller and larger values which are not outliers.

Stepwise multiple regression analysis showed that duration of $\mathrm{CPB}$ was the strongest predictor of $\mathrm{CK}-\mathrm{MB}$ concentration at $1(P<.002)$ and 6 hours $(P<.02)$ and of cTnT concentration at $1(P<.001)$ and 6 hours $(P<$ $.001)$ but at no other time point for either protein.

Effects of PAF antagonist. The mean (SD) area under the curve for CK-MB in the 3 groups was as follows: placebo $=1004(895), 10 \mathrm{mg}$ lexipafant $=1148$ (1275), and $100 \mathrm{mg}$ lexipafant = 1564 (2134) (Fig 3). When log transformed to account for skewed distribution, there was no significant difference among the 3 groups ( $P=.43$, analysis of variance). The mean (SD) area under the curve for $\mathrm{cTnT}$ in the 3 groups was as follows: placebo $=45(74), 10 \mathrm{mg}$ lexipafant $=38(39)$, and $100 \mathrm{mg}$ lexipafant $=62(81)($ Fig 4$)$. When $\log$ transformed to account for skewed distribution, there was no significant difference among the 3 groups $(P=.54$, analysis of variance). By stepwise multiple regression analysis, treatment group (ie, placebo, lowdose, or high-dose lexipafant) did not significantly influence CK-MB or cTnT at any time.

Effects of bilateral ITA grafts. In this study 12 patients received vein grafts only, 87 received one ITA and additional grafts, and 51 received bilateral ITAs and additional grafts. The bilateral and single

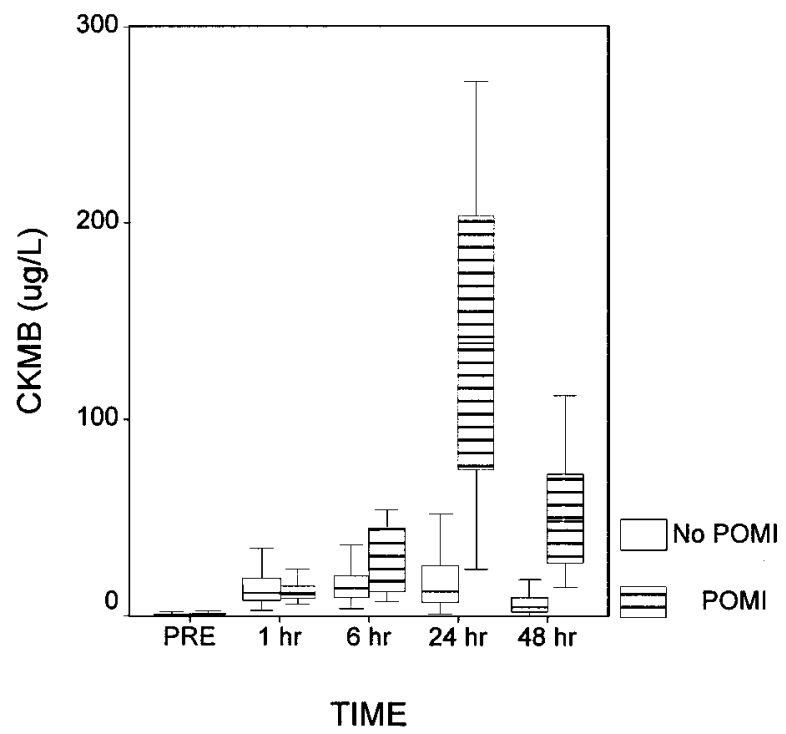

Fig 2. cTnT in patients with and without perioperative myocardial infarction. For explanation of format, see Fig 1.

ITA groups were similar with respect to number of grafts (2.9 [0.4] vs 2.8 [0.7]) and CPB times (69 [12] vs 65 [20] minutes). By stepwise multiple regression analysis, the number of ITA grafts did not significantly influence cTnT concentration at any time. In contrast, the use of 2 ITA grafts accounted for a significant $(P=.02)$ elevation in CK-MB at 6 hours only (Figs 5 and 6).

Effects of endarterectomy. Endarterectomy was performed in 11 patients, of whom 1 died (9\%). Six $(55 \%)$ of the patients undergoing endarterectomy had biochemical evidence of a perioperative myocardial infarct; 4 of these patients had at least minor changes in the postoperative electrocardiogram, and 2 had an unchanged electrocardiogram. Of the 13 biochemically defined perioperative myocardial infarcts, 6 were associated with endarterectomy and 7 were not in the remaining 137 patients (Pearson $\chi^{2} P<.001$ ). Stepwise multiple regression analysis revealed that the performance of endarterectomy resulted in highly significant elevations of CK-MB at 6 hours $(P=.01), 24$ hours $(P$ $<.001)$, and 48 hours $(P<.001)$ and elevations in cTnT at $24(P<.001)$ and 48 hours $(P<.001)$.

Myocardial protection. Fifteen patients received antegrade cold crystalloid cardioplegia and 135 intermittent crossclamp fibrillation. Stepwise multiple regression analysis revealed that method of myocardial protection did not have a significant influence on CKMB or cTnT elevation at any time. 


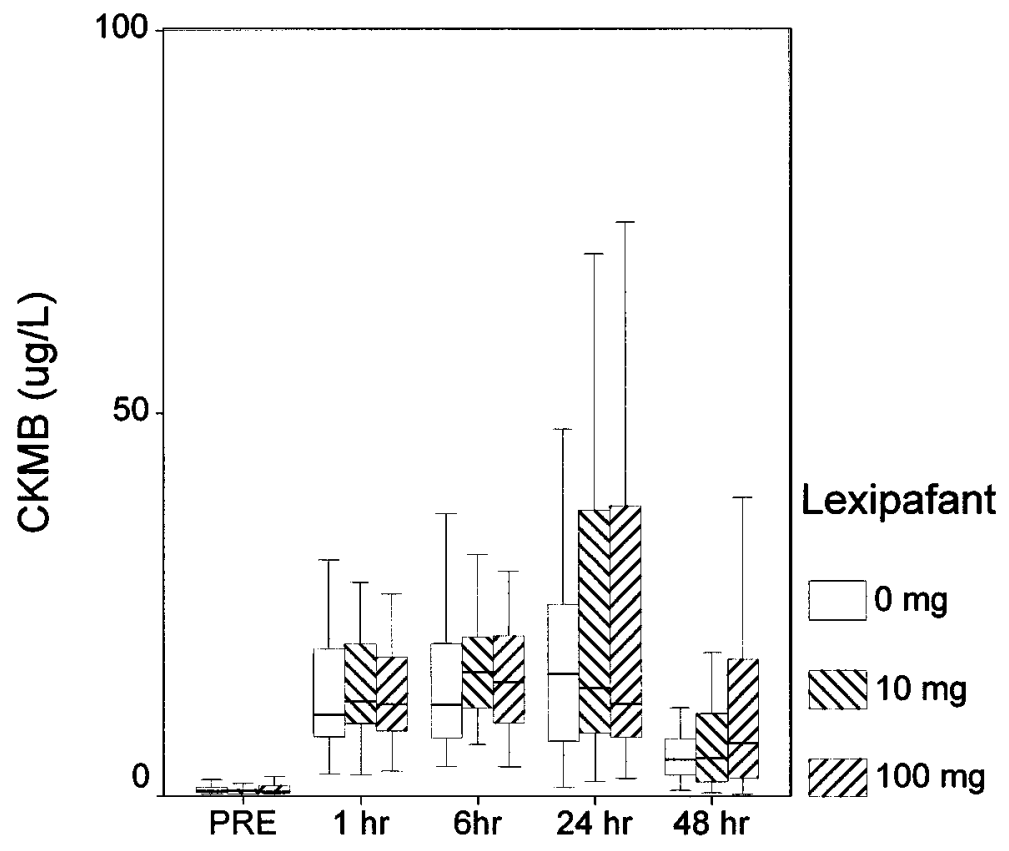

\section{TIME}

Fig 3. CK-MB according to placebo, low-dose, or high-dose PAF antagonist (lexipafant). For explanation of format, see Fig 1.

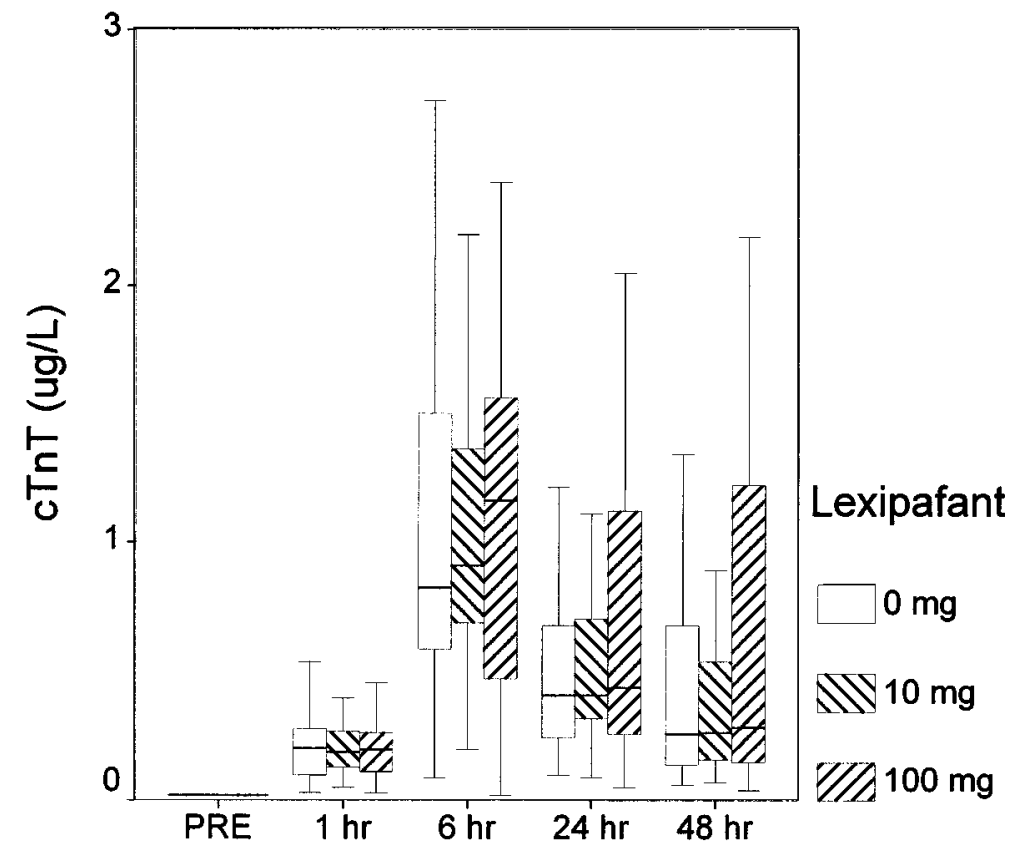

TIME

Fig 4. cTnT according to placebo, low-dose, or high-dose PAF antagonist (lexipafant). For explanation of format, see Fig 1. 


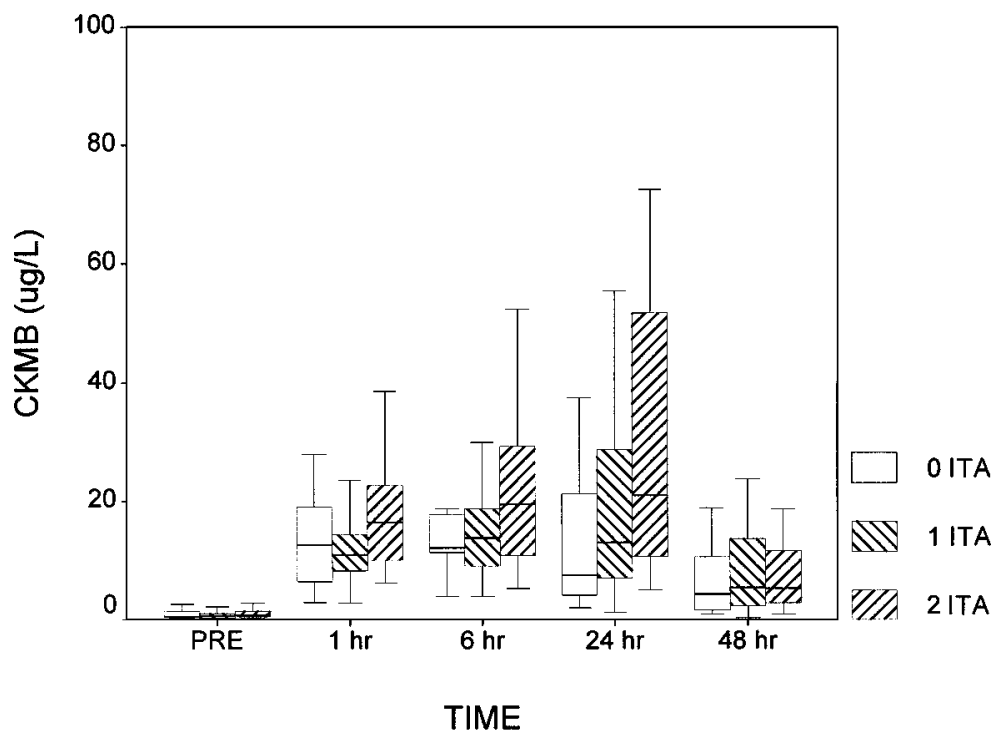

Fig 5. CK-MB according to number of ITA grafts. For explanation of format, see Fig 1.

\section{Discussion}

Detection of perioperative myocardial injury is important for optimizing postoperative management, assessing efficacy of myocardial protective strategies, and auditing clinical outcome. Furthermore, perioperative myocardial infarction may adversely affect long-term prognosis in terms of subsequent ischemic events. ${ }^{21}$

Assesssment of myocardial injury. The prevalence of myocardial injury depends on the method of detection. Functional assessment of contractile status is dependent on loading conditions and cannot reliably distinguish between stunning and irreversible injury. Persistent new Q waves and more than 20\% loss of R waves provide reliable electrocardiographic evidence of myocardial infarction but underestimate the incidence of less severe degrees of myocardial injury. ST-T wave changes are nonspecific, and conduction defects can invalidate interpretation of postoperative electrocardiographic changes.

The conventional limitation of biochemical markers of myocardial injury has been lack of specificity. Currently, the most commonly used marker is CK-MB. However, CK-MB is also released from skeletal muscle, albeit in much lesser quantities than from cardiac muscle. Troponins T, I, and C are part of the tropomyosin complex that regulates muscle contraction and exists in cardiac and skeletal muscle. ${ }^{6}$ The cardiac isoforms $\mathrm{T}$ and I (cTnT, cTnI) have specific protein structures distinct from the skeletal muscle variety. My colleagues and $\mathrm{I}^{1-4}$ have previously reported the value of these markers in quantifying myocardial injury and the effects of various interventions on the release of CK-MB and cTnT in adults and children after cardiac surgery.

Pattern of biochemical response. The pattern of biochemical response in this study is similar to that previously reported by us ${ }^{1-4}$ and others. ${ }^{5-9}$ Even in patients without perioperative myocardial infarction, there were still significant rises in CK-MB and cTnT levels at 6 hours before a decline toward baseline levels by 48 hours. The strongest predictor of elevations in CK-MB and $\mathrm{cTnT}$ at 1 and 6 hours after surgery was the duration of CPB. The functional significance of this early peak in biochemical markers is uncertain but is unlikely to represent truly irreversible myocardial injury. Instead, it is probably due to release of protein from non-structurally bound cytosolic pools, which account for up to $6 \%$ of the total cTnT in the cardiomyocyte. ${ }^{22}$ In the event of true myocardial necrosis, cTnT levels would not peak for at least 12 to 24 hours after the onset of necrosis and would remain elevated for at least 5 days as the contractile apparatus disintegrates. ${ }^{23}$

Prevalence of perioperative myocardial infarction. As discussed earlier, the lowest incidence of perioperative myocardial infarction is usually in studies based on electrocardiographic changes, with a higher incidence in studies based on biochemical criteria. In this study and defined by a continuing rise in CK-MB and cTnT above the level seen at 6 hours, 13 patients (9\%) had biochemical evidence of perioperative myocardial infarction. Although this definition of 


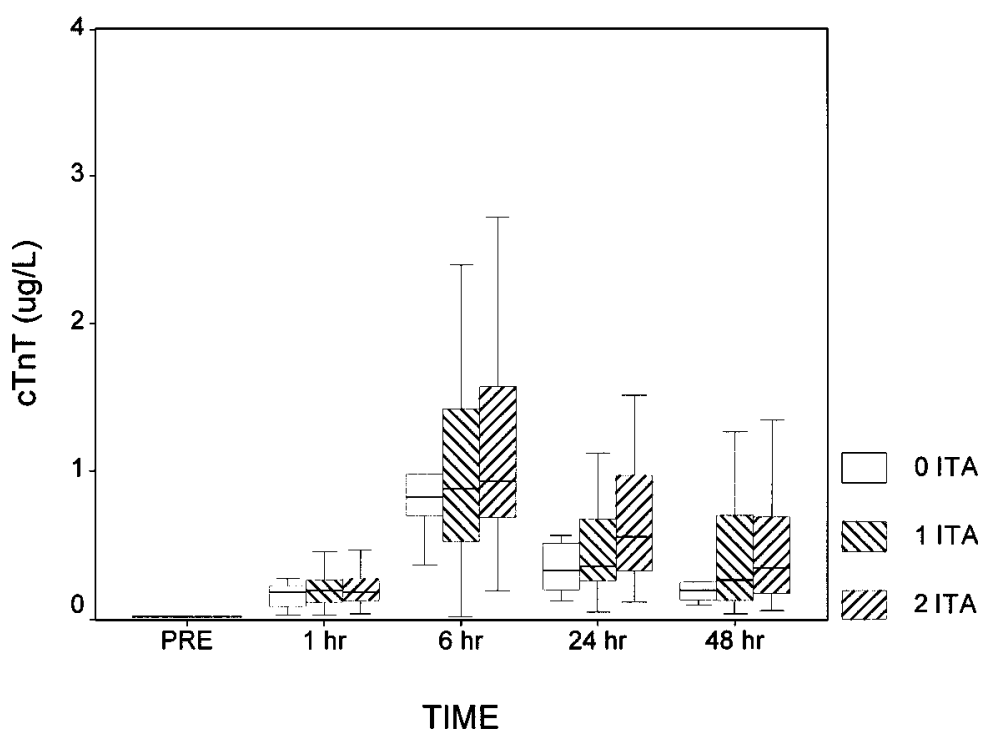

Fig 6. cTnT according to number of ITA grafts. For explanation of format, see Fig 1.

myocardial infarction may underestimate the incidence of smaller focal areas of myocardial necrosis, it is consistent with the expected pattern of protein release in the event of true myocardial infarction. Furthermore, this incidence of biochemically defined myocardial infarction is in keeping with other current reports of infarction in the range of $5 \%$ to $21 \%$ depending on the technique of detection. . $^{5-10}$

Effects of PAF antagonist. The rationale for the use of a PAF antagonist to reduce myocardial injury is based on its ability to reduce general activation and "stickiness" of white blood cells ${ }^{16,17}$ and specifically their role in ischemia-reperfusion injury. ${ }^{11,12,16-20}$ PAF antagonists have been reported to reduce myocardial injury in experimental ischemia-reperfusion injury in terms of improved contractile status, reduced coronary vasoconstriction, and arrhythmia, ${ }^{18-20}$ but to date there has been no confirmatory evidence in the clinical setting.

The higher dose of PAF antagonist administered in this study produces serum levels equivalent to those that have beneficial effects in acute pancreatitis. Nevertheless, in the current study PAF antagonist in low and high doses did not result in a reduction in biochemical evidence of myocardial injury as judged at individual times or by an integrated area under the curve.

Effects of bilateral ITA grafts. Although excellent clinical results are achievable with bilateral ITA grafts, a slightly higher incidence of perioperative myocardial infarction has been reported. ${ }^{24}$ Galbut and colleagues ${ }^{24}$ reported the incidence of perioperative myocardial infarction at $2.1 \%$ in patients receiving bilateral ITA grafts and $1.4 \%$ in patients receiving a single ITA graft. In the current study, there was no difference in myocardial injury in the use of bilateral ITA and single ITA as defined by cTnT levels. Of particular note, however, CK-MB was higher in the bilateral ITA group at 6 hours after $\mathrm{CPB}$, almost certainly reflecting the additional injury to chest wall muscle as a consequence of harvesting both ITA conduits and supporting the increased cardiac specificity of cTnT.

Effects of endarterectomy. Although endarterectomy significantly increases the incidence of perioperative myocardial infarction detected by electrocardiography, ${ }^{25-27}$ there are no prospective studies examining its effect on biochemical markers of myocardial injury and in particular cTnT. In this study, 11 patients underwent endarterectomy, of whom 6 (55\%) had biochemical evidence of myocardial infarction and of whom $1(9 \%)$ died. In the 6 patients with biochemical evidence of infarction, the postoperative electrocardiogram was abnormal in 4 and normal in the remaining 2, suggesting a higher incidence of infarction when defined by biochemical markers. Of the 13 patients with definite perioperative myocardial infarction, 6 had endarterectomy $(46 \%)$ in comparison to 7 of 137 patients $(5 \%)$ without.

Cardioplegia. Only 15 patients had an operation performed with cardioplegia rather than intermittent crossclamping and fibrillation. Regression analysis showed no difference in CK-MB or cTnT release between these 
2 methods of myocardial protection, consistent with what $\mathrm{we}^{2}$ and others have previously reported..$^{27,28} \mathrm{It}$ is, however, possible that the additional 5 to 10 minutes required to perform endarterectomy compromises the safety of the intermittent crossclamp and fibrillation technique. Furthermore, this current study is not able to answer concerns that ITA grafts may not provide as optimal a blood supply as vein grafts to an endarterectomized vessel.

\section{Summary}

This study confirms the usefulness of biochemical markers to assess potentially therapeutic interventions and suggests that cTnT is a more specific marker of myocardial injury than CK-MB. PAF antagonists, in low and high doses, did not reduce perioperative myocardial injury in clinical practice. Bilateral and single ITA grafting results in similar levels of myocardial injury, whereas endarterectomy is frequently associated with biochemical evidence of myocardial injury.

I thank Dr LLoyd Curtis (British Biotech) for invaluable help in organizing and executing the study. I acknowledge my co-workers in the neuropsychological aspects of this study: Stuart Browne, Peter Halligan, and Derrick Wade. I am grateful to Ravi Pillai for participating in the operative aspect of the study and to our cardiac anesthetists for ensuring patients received appropriate treatment. Finally, I thank Tessa Longney for general running of the study and collecting relevant blood samples.

\section{REFERENCES}

1. Taggart DP, Young V, Hooper J, Kemp M, Walesby R, Magee P, et al. Lack of cardioprotective efficacy of allopurinol in coronary artery surgery. Br Heart J 1994;71:177-81.

2. Taggart DP, Bhusari S, Hopper J, Kemp M, Magee P, Wright JE, et al. Intermittent ischaemic arrest and cardioplegia in coronary artery surgery: Coming full circle? Br Heart J 1994;72:136-9.

3. Taggart DP, Jenkins M, Hooper J, Hadjinikolas L, Kemp M, Hue D, et al. Effects of short-term supplementation with coenzyme Q10 on myocardial protection during cardiac surgery. Ann Thorac Surg 1996;61:829-33.

4. Taggart DP, Hadjinikolas L, Hooper J, Albert J, Kemp M, Hue D, et al. Effects of age and ischemic times on biochemical evidence of myocardial injury after pediatric cardiac operations. J Thorac Cardiovasc Surg 1997;113:728-35.

5. Katus HA, Schoeppenthau M, Tanzeem A, Bauer HG, Saggau W, Diederich KW, et al. Non-invasive assessment of perioperative myocardial cell damage by circulating cardiac troponin $\mathrm{T}$. $\mathrm{Br}$ Heart J 1991;65:259-64.

6. Kallner G, Lindblom D, Forssell G, Kallner A. Myocardial release of troponin $\mathrm{T}$ after coronary bypass surgery. Scand $\mathrm{J}$ Thorac Cardiovasc Surg 1994;28:67-72.

7. Carrier M, Pelletier LC, Martineau R, Pellerin M, Solymoss BC. In elective coronary artery bypass grafting, preoperative troponin $\mathrm{T}$ level predicts the risk of myocardial infarction. $\mathrm{J}$ Thorac Cardiovasc Surg 1998;115:1328-34.
8. Bonnefoy E, Filley S, Kirkorian G, Guidollet J, Roriz R, Robin J, et al. Troponin I, troponin T, or creatine kinase-MB to detect perioperative myocardial damage after coronary artery bypass surgery. Chest 1998;114:482-6.

9. Gensini GF, Fusi C, Conti AA, Calamai GC, Montesi GF, Galanti $\mathrm{G}$, et al. Cardiac troponin I and Q-wave perioperative myocardial infarction after coronary artery bypass surgery. Crit Care Med 1998;26:1986-90.

10. Burns RJ, Gladstone PJ, Tremblay PC, Feindel CM, Salter DR, Lipton IH, et al. Myocardial infarction determined by technetium-99m pyrophosphate single-photon tomography complicating elective coronary artery bypass grafting for angina pectoris. Am J Cardiol 1989;63:1429-34.

11. Harlan JM. Neutrophil-mediated vascular injury. Acta Med Scand 1987;715(suppl):123-9.

12. De La Ossa JC, Malago M, Gewertz BL. Neutrophil-endothelial cell binding in neutrophil-mediated tissue injury. J Surg Res 1992;53:103-107.

13. Kirklin JK, Westaby S, Blackstone EH, Kirklin JW, Chenoweth $\mathrm{DE}$, Pacifico AD. Complement and the damaging effects of cardiopulmonary bypass. J Thorac Cardiovasc Surg 1983;86:845-57.

14. Westaby S. Organ dysfunction after cardiopulmonary bypass: a systemic inflammatory reaction by the extracorporeal circuit. Intensive Care Med 1987;13:89-95.

15. Hoshikawa-Fujimura AY, Auleer JOC Jr, Da Rocha TR, et al. PAF-acether, superoxide anion and beta-glucuronidase as parameters of polymorphonuclear cell activation associated with cardiac surgery and cardiopulmonary bypass. Braz J Med Biol Res 1989;22:1077-82.

16. Kubes P, Ibbotson G, Russell J, Wallace JL, Granger DN. Role of platelet activating factor in ischemia/reperfusion-induced leukocyte adherence. Am J Physiol 1990;259:G300-G305.

17. Bazan NG. A signal terminator. Nature 1995;374:501-502.

18. Sawa Y, Schaper J, Roth M, Nagasawa K, Ballagi G, Bleese N, et al. Platelet-activating factor plays an important role in reperfusion injury in myocardium: efficacy of platelet-activating factor receptor antagonist (CV-3988) as compared with leukocytedepleted reperfusion. J Thorac Cardiovasc Surg 1994;108:953-9.

19. Raschke P, Becker BF. Adenosine and PAF dependent mechanisms lead to myocardial reperfusion injury by neutrophils after brief ischemia. Cardiovasc Res 1995;29:569-76.

20. Qayumi AK, English JC, Godin DV, Ansley DM, Loucks EB, Lee $\mathrm{JU}$, et al. The role of platelet-activating factor in regional myocardial ischemia-reperfusion injury. Ann Thorac Surg 1998; 65:1690-7.

21. Guiteras Val P, Pelletier LC, Hernandez MG, Jais JM, Chaitman BR, Dupras G, et al. Diagnostic criteria and prognosis of perioperative myocardial infarction following coronary bypass. J Thorac Cardiovasc Surg 1983;86:878-86.

22. Remppis A, Scheffold T, Greten J, et al. Intracellular compartmentation of troponin $\mathrm{T}$ : release kinetics after global ischemia and calcium paradox in the isolated perfused rat heart. J Mol Cell Cardiol 1995;27:793-803.

23. Rottbauer W, Greten T, Muller-Bardorff M, Remppis A, Zehelein J, Grunig E, et al. Troponin T: a diagnostic marker for myocardial infarction and minor cell damage. Eur Heart J 1996;17(suppl F):3-8.

24. Galbut DL, Traad EA, Dorman MJ, De Witt PL, Larsen PB, Kurlansky PA, et al. Coronary bypass grafting in the elderly: single versus bilateral internal mammary artery grafts. J Thorac Cardiovasc Surg 1993;106:128-36.

25. Brenowitz JB, Kayser KL, Johnson WD. Results of coronary 
artery endarterectomy and reconstruction. J Thorac Cardiovasc Surg 1988;95:1-10.

26. Livesay JJ, Cooley DA, Hallman GL, Reul GJ, Ott DA, Duncan $\mathrm{JM}$, et al. Early and late results of coronary endarterectomy: analysis of 3,369 patients. J Thorac Cardiovasc Surg 1986;92:649-60.

27. Christenson JT, Simonet F, Schmuziger M. Extensive endarterectomy of the left anterior descending coronary artery combined with coronary artery bypass grafting. Coron Artery Dis 1995;6:731-7.
28. Anderson JR, Hossein-Nia M, Kallis P, Pye M, Holt DW, Murday $\mathrm{AJ}$, et al. Comparison of two strategies for myocardial management during coronary artery operations. Ann Thorac Surg 1994;58:768-72.

29. Cohen AS, Hadjinikolaou L, McColl A, Richmond W, Sapsford RA, Glenville BE. Lipid peroxidation, antioxidant status and troponin-T following cardiopulmonary bypass: a comparison between intermittent crossclamp with fibrillation and crystalloid cardioplegia. Eur J Cardiothorac Surg 1997;12:248-53.

\section{Bound volumes available to subscribers}

Bound volumes of The Journal of Thoracic and Cardiovascular Surgery are available to subscribers (only) for the 2000 issues from the Publisher, at a cost of $\$ 134.00$ for domestic, $\$ 165.85$ for Canadian, and $\$ 155.00$ for international subscribers for Vol 119 (January-June) and Vol 120 (July-December). Shipping charges are included. Each bound volume contains a subject and author index and all advertising is removed. Copies are shipped within 60 days after publication of the last issue of the volume. The binding is durable buckram with the Journal name, volume number, and year stamped in gold on the spine. Payment must accompany all orders. Contact Mosby, Subscription Customer Service, 6277 Sea Harbor Dr, Orlando, FL 32887,USA; phone 800-654-2452 or 407-345-4000.

Subscriptions must be in force to qualify. Bound volumes are not available in place of a regular Journal subscription. 